\title{
CRISPR/Cas9: A Robust Genome-Editing Tool with Versatile Functions and Endless Application
}

\author{
Baohong Zhang \\ Department of Biology, East Carolina University, Greenville, NC 27858, USA; zhangb@ecu.edu
}

Received: 13 July 2020; Accepted: 17 July 2020; Published: 20 July 2020

Since a potential genome editing tool was first recognized in 2012 [1,2], the CRISPR/Cas9 system has been becoming a powerful and robust genome editing tool for gene function study and crop improvement. Over the past decade, as new Cas enzymes have been identified, current Cas 9 enzymes modified, and new bioinformatics tools developed, CRISPR/Cas9-based research has been developing extremely quickly. Particularly, the modification of Cas enzymes has significantly boosted the application potentials of CRISPR/Cas9 genome editing [3]. Although there are many other Cas enzymes identified and utilized in genome editing, the CRISPR/Cas9 system currently refers to any CRISPR/Cas system, including Cas12 and Cas13, majorly due to the fact that Cas9 is the first and most commonly used Cas enzyme in genome editing [4]. At present, CRISPR/Cas9 genome editing has been widely used in many plant species, including both model plant species and agriculturally important crops, such as wheat [5], cotton [6] and soybean [7], not only for gene functional study but also for crop improvement. To facilitate the quick development and application of CRISPR/Cas9 genome editing. We edited this Special Issue of "Genome Editing in Plants". In a short time period, this Special Issue attracted a lot of attention from the scientific field and industries. Finally, after the expert peer review, a total of 15 papers were accepted to be published in this Special Issue of International Journal of Molecular Sciences.

Among the 15 published papers, three are timely review papers. Jansing and colleagues (2019) reviewed the technical and practical consideration of genome editing in agriculture, particularly focusing on the current delivery method of the CRISPR/Cas9 system into plant cells and their regeneration methods. They also discussed the suitability of CRISPR/Cas9 for improving different traits of agriculturally important crops [8]. Among all crops, significant progress has been made in rice using CRISPR/Cas genome editing technology. In a review written by Fiaz and colleagues (2019), they reviewed the current status of CRISPR/Cas9 on rice improvement, particularly on rice grain quality improvement [9]. Increasing CRISPR/Cas9 on-target efficiency and reducing the off-target effect is always a major topic for genome editing. A lot of offers have been added into this field in the past half-decade. In this Special Issue, Hajiahmadi and colleagues (2019) reviewed the major strategies for reducing the off-target effect of CRISPR/Cas9. They thought that the combination of single guide RNA (sgRNA) and a ligand-dependent aptazyme strategy may be a great strategy for decreasing the frequency of off-target mutations in plants [10].

The remaining 12 research articles are associated with 12 different plant species, including rice [11], cotton [12], wheat [13,14], Brassica napus [15], soybean [16], sweet potato [17], cowpea [18], tomato [19], potato [19], chicory [20] and model plant Arabidopsis [21], as well as alga Chlamydomonas reinhardtii [22]. From here, it is clearly seen that more and more research has been focused on agriculturally important crops. The majority of these studies employed traditional CRISPR/Cas9 technology to knock out an individual gene, except one study, which employed the CRISPR/Cas9 base editor to create a transgene-free genome editing tomato and potato [19]. Among these studies, the majority of them worked on agriculturally important traits. For example, Wang and colleagues (2019) studied the function of IbGBSSI and IbSBEII genes in starch biosynthesis in sweet potato by CRISPR/Cas9 genome 
editing [17]. Chen and colleagues investigated the function of the M-locus protein kinase (MLPK) BnaMLPKs, the functional homolog of BrMLPKs in Brassica rapa [15]. Chen and colleagues used Arabidopsis as a model to study the role of DPA4 and SOD7 genes in seed development and response to abiotic stress [21]. All these studies have provided new tools and/or new insight into our understanding of agriculturally important traits.

Conflicts of Interest: The authors declare no conflict of interest.

\section{References}

1. Gasiunas, G.; Barrangou, R.; Horvath, P.; Siksnys, V. Cas9-crRNA ribonucleoprotein complex mediates specific DNA cleavage for adaptive immunity in bacteria. Proc. Natl. Acad. Sci. USA 2012, 109, E2579-E2586. [CrossRef] [PubMed]

2. Jinek, M.; Chylinski, K.; Fonfara, I.; Hauer, M.; Doudna, J.A. A programmable dual-RNA-guided DNA endonuclease in adaptive bacterial i9mmunity. Science 2012, 337, 816-821. [CrossRef] [PubMed]

3. Zhang, D.; Zhang, B. SpRY: Engineered CRISPR/Cas9 Harnesses New Genome-Editing Power. Trends Genet. 2020, 36, 546-548. [CrossRef] [PubMed]

4. Makarova, K.S.; Wolf, Y.I.; Iranzo, J.; Shmakov, S.A.; Alkhnbashi, O.S.; Brouns, S.J.J.; Charpentier, E.; Cheng, D.; Haft, D.H.; Horvath, P.; et al. Evolutionary classification of CRISPR-Cas systems: A burst of class 2 and derived variants. Nat. Rev. Microbiol. 2020, 18, 67-83. [CrossRef] [PubMed]

5. Shan, Q.; Wang, Y.; Li, J.; Zhang, Y.; Chen, K.; Liang, Z.; Zhang, K.; Liu, J.; Xi, J.J.; Qiu, J.-L.; et al. Targeted genome modification of crop plants using a CRISPR-Cas system. Nat. Biotechnol. 2013, 31, 686-688. [CrossRef]

6. Li, C.; Unver, T.; Zhang, B. A high-efficiency CRISPR/Cas9 system for targeted mutagenesis in Cotton (Gossypium hirsutum L.). Sci. Rep. 2017, 7, 43902. [CrossRef]

7. Jacobs, T.B.; Lafayette, P.R.; Schmitz, R.J.; Parrott, W.A. Targeted genome modifications in soybean with CRISPR/Cas9. BMC Biotechnol. 2015, 15, 16. [CrossRef]

8. Jansing, J.; Schiermeyer, A.; Schillberg, S.; Fischer, R.; Bortesi, L. Genome Editing in Agriculture: Technical and Practical Considerations. Int. J. Mol. Sci. 2019, 20, 2888. [CrossRef]

9. Fiaz, S.; Ahmad, S.; Noor, M.A.; Wang, X.; Younas, A.; Riaz, A.; Riaz, A.; Ali, F. Applications of the CRISPR/Cas9 System for Rice Grain Quality Improvement: Perspectives and Opportunities. Int. J. Mol. Sci. 2019, 20, 888. [CrossRef]

10. Hajiahmadi, Z.; Movahedi, A.; Wei, H.; Li, D.; Orooji, Y.; Ruan, H.; Zhuge, Q. Strategies to Increase On-Target, and Reduce Off.-Target. Effects of the CRISPR/Cas9 System in Plants. Int. J. Mol. Sci. 2019, $20,3719$.

11. Wu, T.-M.; Huang, J.-Z.; Oung, H.-M.; Hsu, Y.T.; Tsai, Y.-C.; Hong, C.-Y. $\mathrm{H}_{2} \mathrm{O}_{2}$-Based Method for Rapid Detection of Transgene-Free Rice Plants from Segregating CRISPR/Cas9 Genome-Edited Progenies. Int. J. Mol. Sci. 2019, 20, 3885. [CrossRef] [PubMed]

12. Zhu, S.; Yu, X.; Li, Y.; Sun, Y.; Zhu, Q.; Sun, J. Highly Efficient Targeted Gene Editing in Upland Cotton Using the CRISPR/Cas9 System. Int. J. Mol. Sci. 2018, 19, 3000. [CrossRef]

13. Slim, A.; Piarulli, L.; Kourda, H.C.; Rouaissi, M.; Robbana, C.; Chaabane, R.; Pignone, D.; Montemurro, C.; Mangini, G. Genetic Structure Analysis of a Collection of Tunisian Durum Wheat Germplasm. Int. J. Mol. Sci. 2019, 20, 3362. [CrossRef] [PubMed]

14. Zhang, S.; Zhang, R.; Gao, J.; Gu, T.; Song, G.; Li, W.; Li, D.; Li, Y.; Li, G. Highly Efficient and Heritable Targeted Mutagenesis in Wheat via the Agrobacteriumtumefaciens-Mediated CRISPR/Cas9 System. Int. J. Mol. Sci. 2019, 20, 4257. [CrossRef]

15. Chen, F.; Yang, Y.; Li, B.; Liu, Z.; Khan, F.; Zhang, T.; Zhou, G.; Tu, J.; Shen, J.; Yi, B.; et al. Functional Analysis of M-Locus Protein Kinase Revealed a Novel Regulatory Mechanism of Self-Incompatibility in Brassica napus L. Int. J. Mol. Sci. 2019, 20, 3303. [CrossRef] [PubMed]

16. Cai, Y.; Chen, L.; Sun, S.; Wu, C.; Yao, W.; Jiang, B.; Han, T.; Hou, W. CRISPR/Cas9-Mediated Deletion of Large Genomic Fragments in Soybean. Int. J. Mol. Sci. 2018, 19, 3835. [CrossRef]

17. Wang, H.; Wu, Y.; Zhang, Y.; Yang, J.; Fan, W.; Zhang, H.; Zhao, S.; Yuan, L.; Zhang, P. CRISPR/Cas9-Based Mutagenesis of Starch Biosynthetic Genes in Sweet Potato (Ipomoea Batatas) for the Improvement of Starch Quality. Int. J. Mol. Sci. 2019, 20, 4702. [CrossRef] 
18. Ji, J.; Zhang, C.; Sun, Z.; Wang, L.; Duanmu, D.; Fan, Q. Genome Editing in Cowpea Vigna unguiculata Using CRISPR-Cas9. Int. J. Mol. Sci. 2019, 20, 2471. [CrossRef]

19. Veillet, F.; Perrot, L.; Chauvin, L.; Kermarrec, M.-P.; Guyon-Debast, A.; Chauvin, J.-E.; Nogué, F.; Mazier, M. Transgene-Free Genome Editing in Tomato and Potato Plants Using Agrobacterium-Mediated Delivery of a CRISPR/Cas9 Cytidine Base Editor. Int. J. Mol. Sci. 2019, 20, 402. [CrossRef]

20. Bernard, G.; Gagneul, D.; Dos Santos, H.A.; Etienne, A.; Hilbert, J.-L.; Rambaud, C. Efficient Genome Editing Using CRISPR/Cas9 Technology in Chicory. Int. J. Mol. Sci. 2019, 20, 1155. [CrossRef]

21. Chen, S.; Zhang, N.; Zhang, Q.; Zhou, G.; Tian, H.; Hussain, S.; Ahmed, S.; Wang, T.; Wang, S. Genome Editing to Integrate Seed Size and Abiotic Stress Tolerance Traits in Arabidopsis Reveals a Role for DPA4 and SOD7 in the Regulation of Inflorescence Architecture. Int. J. Mol. Sci. 2019, 20, 2695. [CrossRef] [PubMed]

22. Guzmán-Zapata, D.; Sandoval-Vargas, J.M.; Macedo-Osorio, K.S.; Salgado-Manjarrez, E.; Castrejón-Flores, J.L.; Oliver-Salvador, M.D.C.; Durán-Figueroa, N.V.; Nogué, F.; Badillo-Corona, J. Efficient Editing of the Nuclear APT Reporter Gene in Chlamydomonas reinhardtii via Expression of a CRISPR-Cas9 Module. Int. J. Mol. Sci. 2019, 20, 1247. [CrossRef] [PubMed]

(C) 2020 by the author. Licensee MDPI, Basel, Switzerland. This article is an open access article distributed under the terms and conditions of the Creative Commons Attribution (CC BY) license (http://creativecommons.org/licenses/by/4.0/). 